\title{
Development and Optimisation of HILIC-LC-MS Method for Determination of Carbohydrates in Fermentation Samples
}

\author{
Dmitri Pismennõi ${ }^{1,2, * \mathbb{C}}$, Vassili Kiritsenko ${ }^{1,2}{ }^{,}$Jaroslav Marhivka ${ }^{1,2}$, Mary-Liis Kütt $^{1} \mathbb{D}$ and Raivo Vilu ${ }^{1}$ \\ 1 Center of Food and Fermentation Technologies (TFTAK), Akadeemia tee 15A, \\ 12618 Tallinn, Estonia; vassili@tftak.eu (V.K.); jaroslav@tftak.eu (J.M.); maryliis@tftak.eu (M.-L.K.); \\ raivo@tftak.eu (R.V.) \\ 2 Department of Chemistry and Biotechnology, Tallinn University of Technology, Akadeemia tee 15, \\ 12618 Tallinn, Estonia \\ * Correspondence: dmitri@tftak.eu; Tel.: +372-53-541-667
}

Citation: Pismennõi, D.; Kiritsenko, V.; Marhivka, J.; Kütt, M.-L.; Vilu, R. Development and Optimisation of HILIC-LC-MS Method for Determination of Carbohydrates in Fermentation Samples. Molecules 2021, 26, 3669. https://doi.org/ $10.3390 /$ molecules26123669

Academic Editor: Stefano Dall'Acqua

Received: 21 April 2021

Accepted: 12 June 2021

Published: 16 June 2021

Publisher's Note: MDPI stays neutral with regard to jurisdictional claims in published maps and institutional affiliations.

Copyright: (c) 2021 by the authors. Licensee MDPI, Basel, Switzerland. This article is an open access article distributed under the terms and conditions of the Creative Commons Attribution (CC BY) license (https:// creativecommons.org/licenses/by/ $4.0 /)$.

\begin{abstract}
Saccharides are the most common carbon source for Streptococcus thermophilus, which is a widely used bacterium in the production of fermented dairy products. The performance of the strain is influenced by the consumption of different saccharides during fermentation. Therefore, a precise measurement of the concentrations of saccharides in the fermentation media is essential. An 18-min long method with limits of quantitation in the range of $0.159-0.704 \mathrm{mg} / \mathrm{L}$ and with ${ }^{13} \mathrm{C}$ labelled internal standards employing hydrophilic interaction chromatography coupled to mass spectrometric detection-(HILIC-LC-MS) allowed for simultaneous quantification of five saccharides: fructose, glucose, galactose, sucrose, and lactose in the fermentation samples. The method included a four-step sample preparation protocol, which could be easily applied to high-throughput analysis. The developed method was validated and applied to the fermentation samples produced by Streptococcus thermophilus.
\end{abstract}

Keywords: saccharides; HILIC-LC-MS; Streptococcus thermophilus; fermentation

\section{Introduction}

Streptococcus thermophilus is a gram-positive facultative anaerobic bacterium mostly known for its role in the production of fermented dairy products. As a part of the lactic acid bacteria (LAB) group, it is a widely studied and well-known microorganism. As production of lactic acid by $S$. thermophilus is dependent on carbohydrate utilisation, the choice of available carbohydrate is usually dictated by strain ability to digest certain disaccharidesmainly sucrose and lactose [1]. Bacterial consumption of monosaccharides-fructose, glucose. and galactose, was found to be suppressed in most common strains. Nevertheless, the mutant strains, able to consume monosaccharides, were created to study the alternative ways for lactic acid production by utilisation of low-molecular carbohydrates [2-4].

Carbohydrates are a vast class of chemical compounds with a similar structure comprised of either furanose or pyranose skeleton core. Carbohydrate analysis employing chromatography has a long history starting from paper partition chromatography of selected monosaccharides in 1949 [5]. The advances in the chromatographic field have helped to achieve better separation and selectivity [6,7]. The main path to analyse carbohydrates was to use either gas chromatography with derivatisation of saccharides or liquid chromatography employing ion-exchange resins [8]. The development of novel stationary phases for both gas and liquid chromatography increased the number of applications where carbohydrate analysis could be performed from samples obtained from various sources, i.e., raw nutritional materials, animals, bacteria, humans, and so forth [9-12]. At the same time, developments in ion chromatography and electrophoresis allowed to measure carbohydrates in similar matrices creating the alternative ways for the measurements 
of saccharides [13-16]. Nowadays, the most commonly used method is to measure carbohydrates to use ion-exchange resin with a refractive index (RI) detector, as carbohydrates do not have any chromophores. The use of this combination is shown in Association of Official Analytical Chemists (AOAC) or International Organization for Standardization (ISO) methods [17]. The main disadvantage with RI-based detection is a relatively low selectivity, sensitivity, and elution program restriction compared to more advanced detection techniques such as evaporative light scattering detector (ELSD) [18,19], charged aerosol detection (CAD) [20] or mass spectrometric (MS) detector [21-23]. Out of advanced methods, MS-based detection offers the most selectivity as active mass filtration could clean up a substantial portion of noise interference originated from the sample matrix [24]. Therefore, the liquid chromatography coupled to mass spectrometer (LC-MS) system became a prominent choice to perform carbohydrate analysis with little to no extensive sample preparation $[25,26]$.

The aim of this work was to develop and validate a rapid and sensitive method for the quantitative determination of five saccharides: fructose, glucose, galactose, sucrose, and lactose, by employing a rapid, selective, and sensitive methodology based on hydrophilic interaction chromatography coupled to mass spectrometric detection (HILIC-LC-MS) and isotopically labelled glucose and lactose as internal standards. The method development included optimisation of sample preparation, validation and application of the method towards the determination of carbohydrates metabolised by $S$. thermophilus in fermentation broth samples.

\section{Results and Discussion}

\subsection{Chromatographic and Mass Spectrometric Optimisation}

The initial screening involved testing of the performance of several columns with hydrophilic interaction (HILIC) stationary phase. The testing of Waters BEH HILIC and BEH Amide revealed that even though the columns are clearly capable of separation between mono- and disaccharides, the inter-class separation of closely matched carbohydrates is impossible (Figure 1).

During method scouting, it became evident that BEH HILIC column could not achieve an acceptable separation of 3 monosaccharides of interest. Employing Waters BEH Amide column showed the separation between fructose and glucose-galactose pair close to the baseline. The separation of the glucose-galactose pair requires more resolving power as the epimer separation is proven to be complex. The acceptable separation between epimers was reached using Phenomenex Luna Omega Sugar column, which allowed a repeatable and precise determination of closely eluting glucose and galactose (Figure 2).

To improve the sensitivity of measured analytes, the decision to enrich the mobile phases with guanidine hydrochloride solution was made to facilitate the formation of $[\mathrm{M}+$ $\mathrm{Cl}]^{-}$adduct instead of $[\mathrm{M}-\mathrm{H}]^{-}$ion. The addition of chloride ion to saccharide molecules provided better ionisation, cleaner spectra at the baseline level (Table S1). It thus decreased the amount of sample injected on the column to achieve a satisfactory chromatographic and mass spectrometric result $[27,28]$. The variations in flow rate were also studied as the mock-up method was transferred from the column with a larger inner diameter, making it incompatible with the current column choice. Therefore, several different flow rates were evaluated to achieve optimal separation between all analytes: 300, 313 and $350 \mu \mathrm{L} / \mathrm{min}$ (Figure S1-S3). The flow rate $313 \mu \mathrm{L} / \mathrm{min}$ resulted in the most optimal separation among targeted carbohydrates. The column temperature was also studied, and two temperatures were tested: 25 and $35^{\circ} \mathrm{C}$. The higher temperature was ruled out as unfavoured due to more unsatisfactory performance in terms of chromatographic separations, which was in accordance with reports in the literature [29].

\subsection{Sample Preparation Optimisation and Measurement of Fermentation Samples}

Several variants of sample preparation were proposed during initial consideration for adequate sample preparation for maximum elimination of matrix components (Table 1). 

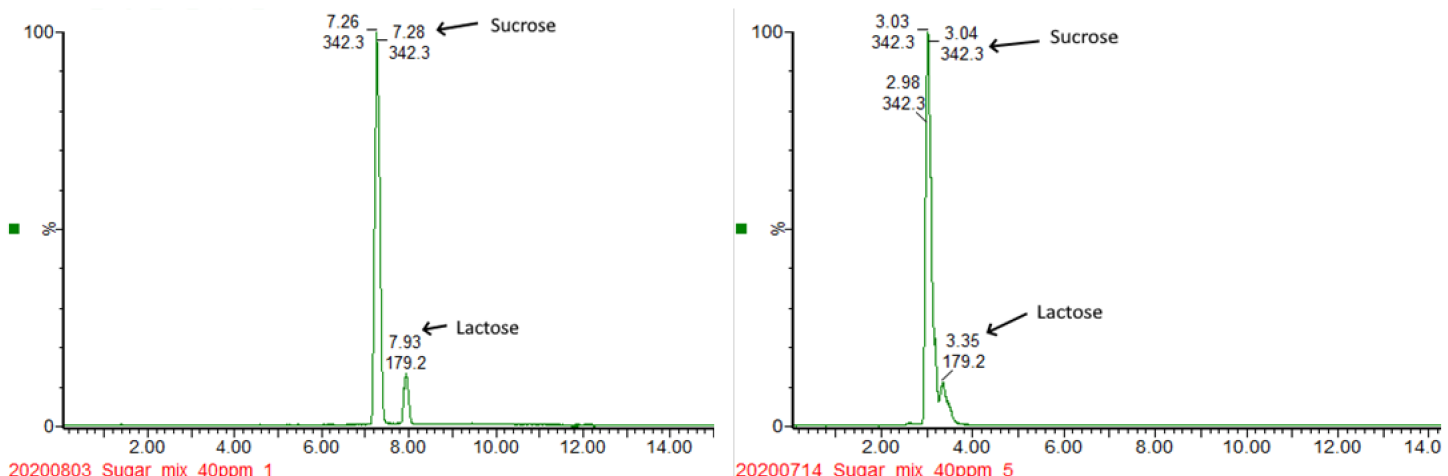

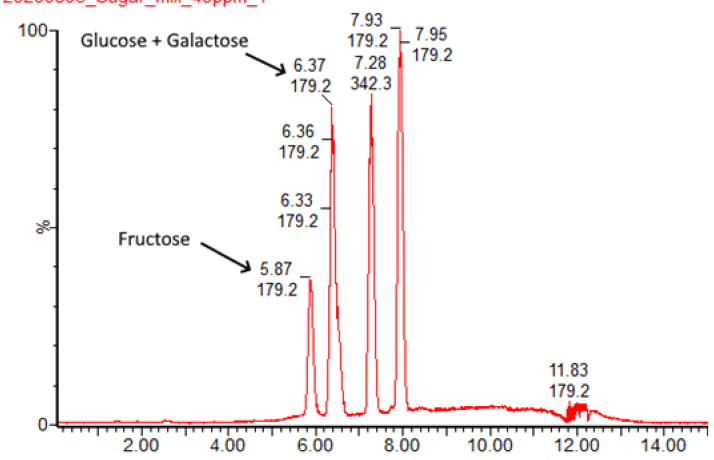

(a)

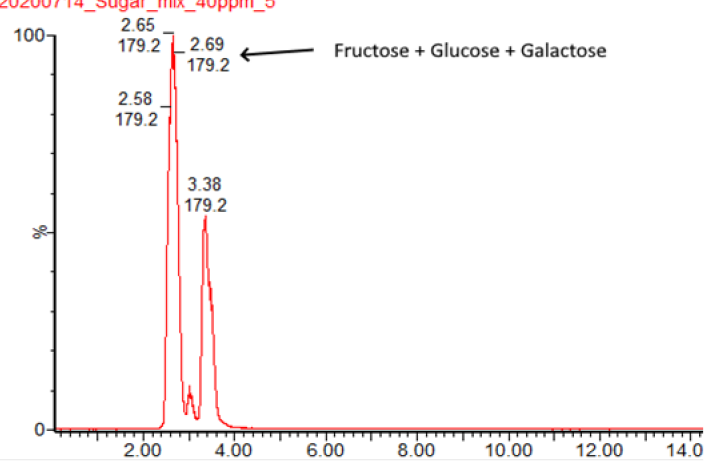

(b)

Figure 1. (a) Separation of mono- and disaccharides on Waters BEH Amide column with mobile phases containing $0.1 \%$ $\mathrm{NH}_{4} \mathrm{OH}$; The elution was achieved using gradient elution at $170 \mu \mathrm{L} / \mathrm{min}$ flow rate. Solvents were: $\mathrm{A}-\mathrm{MilliQ}+0.1 \%$ $\mathrm{NH}_{4} \mathrm{OH}, \mathrm{B}-\mathrm{MeCN}+0.1 \% \mathrm{NH}_{4} \mathrm{OH}$. Gradient program was: 0.0-10 min linear ramp 0.1-60\% A, 10.01-25.00 hold at 0.1\% A. The detection was performed in Single-Ion-Reaction (SIR) mode (b) Separation of mono- and disaccharides on Waters BEH HILIC column with mobile phases containing neat solvents. The elution was achieved using gradient elution at $170 \mu \mathrm{L} / \mathrm{min}$ flow rate. Solvents were: A-MilliQ, B-MeCN. Gradient program was: 0.0-20 min linear ramp 0.1-40\% A, 20.01-30.00 hold at $0.1 \%$ A. The detection was performed in Single-Ion-Reaction (SIR) mode at a concentration level of $10 \mu \mathrm{g} / \mathrm{mL}$ for all saccharides.

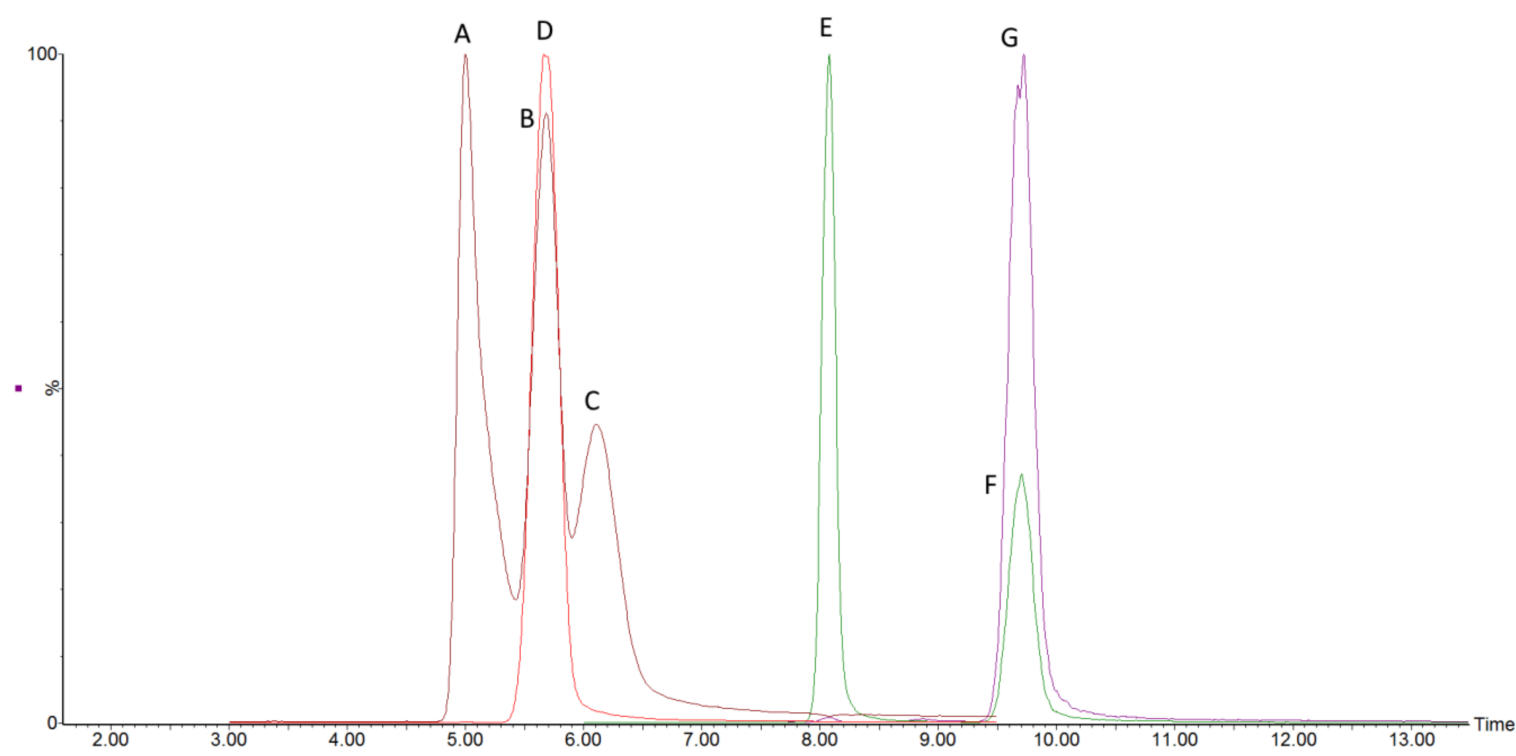

Figure 2. The representative chromatogram of separated mono- and disaccharides with internal ${ }^{13} \mathrm{C}$-labeled standards on the Luna Omega Sugar column. Peaks are labelled as: A—fructose, B-glucose, C—galactose, D—glucose- ${ }^{13} \mathrm{C}_{6}, \mathrm{E}-\mathrm{sucrose}$, $\mathrm{F}$-lactose and $\mathrm{G}$-lactose- $-{ }^{13} \mathrm{C}_{6}$. Peak heights are normalised. 
Table 1. Comparison of sample preparation protocols.

\begin{tabular}{|c|c|c|c|c|c|c|}
\hline $\begin{array}{l}\text { Protocol } \\
\text { Nr. }\end{array}$ & 1 & 2 & 3 & 4 & 5 & 6 \\
\hline Step 1 & \multicolumn{5}{|c|}{ Dilute 100 times with MilliQ } & $\begin{array}{c}\text { Dilute } 50 \text { times with } \\
\text { MilliQ }\end{array}$ \\
\hline Step 2 & \multicolumn{6}{|c|}{ Centrifuge at $14000 \mathrm{rpm}$ for $10 \mathrm{~min}$} \\
\hline Step 3 & $\begin{array}{l}\text { Filter through } \\
0.2 \mu \mathrm{m} \text { filter }\end{array}$ & $\begin{array}{l}\text { Dilute } 2 \text { times } v \\
\text { mixture cont }\end{array}$ & $\begin{array}{l}\text { MeCN: MilliQ } \\
\text { ing }{ }^{13} \mathrm{C} \text { ISTD }\end{array}$ & $\begin{array}{l}\text { Pass through } 1 \\
\text { kDa MWCO } \\
\text { filter }\end{array}$ & $\begin{array}{l}\text { Pass through } 3 \\
\text { kDa MWCO filter }\end{array}$ & $\begin{array}{l}\text { Dilute } 4 \text { times with } \\
\text { MeCN: MilliQ } \\
\text { mixture containing } \\
{ }^{13} \mathrm{C} \text { ISTD }\end{array}$ \\
\hline Step 4 & $\begin{array}{l}\text { Dilute } 2 \text { times } \\
\text { with MeCN: } \\
\text { MilliQ mixture } \\
\text { containing }{ }^{13} \mathrm{C} \\
\text { ISTD }\end{array}$ & $\begin{array}{l}\text { Pass through } \\
\text { Isolute PLD+ } \\
\text { cartridge }\end{array}$ & $\begin{array}{l}\text { Pass through } \\
\text { Isolute } \mathrm{NH}_{2} \\
\text { cartridge }\end{array}$ & \multicolumn{2}{|c|}{$\begin{array}{l}\text { Dilute } 2 \text { times with MeCN: MilliQ } \\
\text { mixture containing C13 ISTD }\end{array}$} & $\begin{array}{l}\text { Pass through Isolute } \\
\mathrm{NH}_{2} \text { cartridge }\end{array}$ \\
\hline
\end{tabular}

As the protocols were being tested firstly with a simulated matrix composed of chemically defined medium (CDM) [30] and external standards, it was found that variants 2, 3, 4 and 6 did not produce expected results as analytes were detected in lower amount compared to other protocols or no analytes of interest were found during the measurement (Table S2). Protocol $\mathrm{nr} 1$ and 5 were chosen for additional evaluation as their performance with simulated matrix was found to be acceptable. The optimised protocols nr. 1 and 5 were applied towards harvested fermentation broth. It was found that protocol $\mathrm{nr} 1$ produced a higher number of impurities which negatively affected MS performance by leaving more residue on the source cone compared to protocol $\mathrm{nr} 5$, which included the usage of molecular weight cut-off filters (Figure 3).

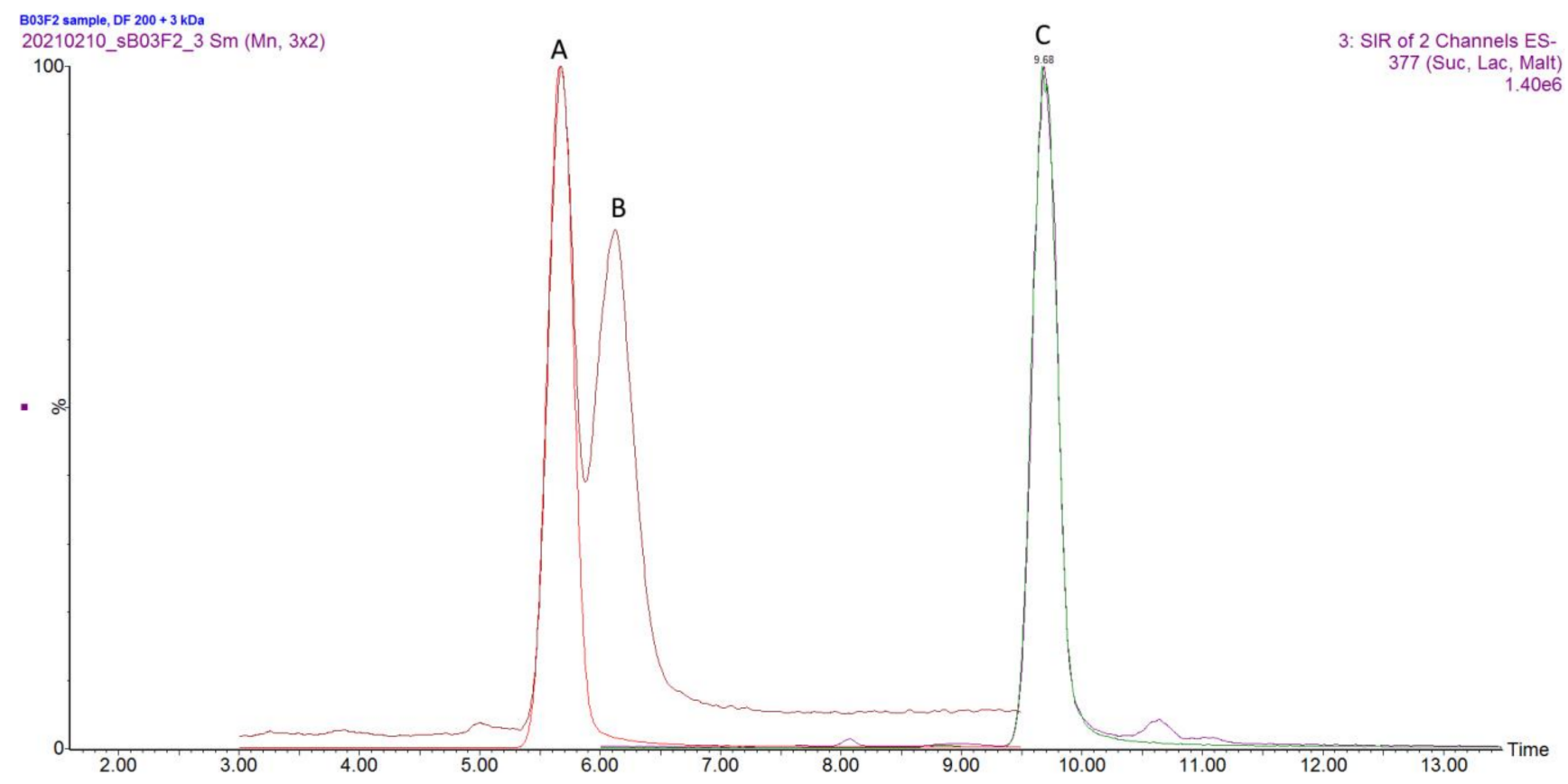

Figure 3. The overlaid chromatogram of the fermented sample subjected to extraction protocol nr. 5. Peaks are labelled as follows: A-Glucose and Glucose- $-{ }^{13} \mathrm{C}_{6}$, B-Galactose, C-Lactose and Lactose- ${ }^{13} \mathrm{C}_{6}$.

After sample preparation protocol optimisation was completed and sample preparation protocol $\mathrm{nr} 5$ was chosen as the primary option to perform sample preparation. Six samples obtained during the fermentation process at different time points were analysed for carbohydrate content (Table 2). 
Table 2. Description of the harvested fermentation samples produced by $S$. thermophilus.

\begin{tabular}{ccc}
\hline Sample Name & Sampling Time Point, $\mathbf{h}$ & Carbohydrate Source \\
\hline BO3F1_1 & 24 & Sucrose \\
B3F1_2 & 24 & Sucrose \\
BO3F2_1 & 24 & Lactose \\
B3F2_2 & 24 & Lactose \\
B3F1H0 & 0 & Lactose \\
B3F2H0 & 0 & Sucrose \\
\hline
\end{tabular}

The samples were injected in triplicates. (Figure 4).

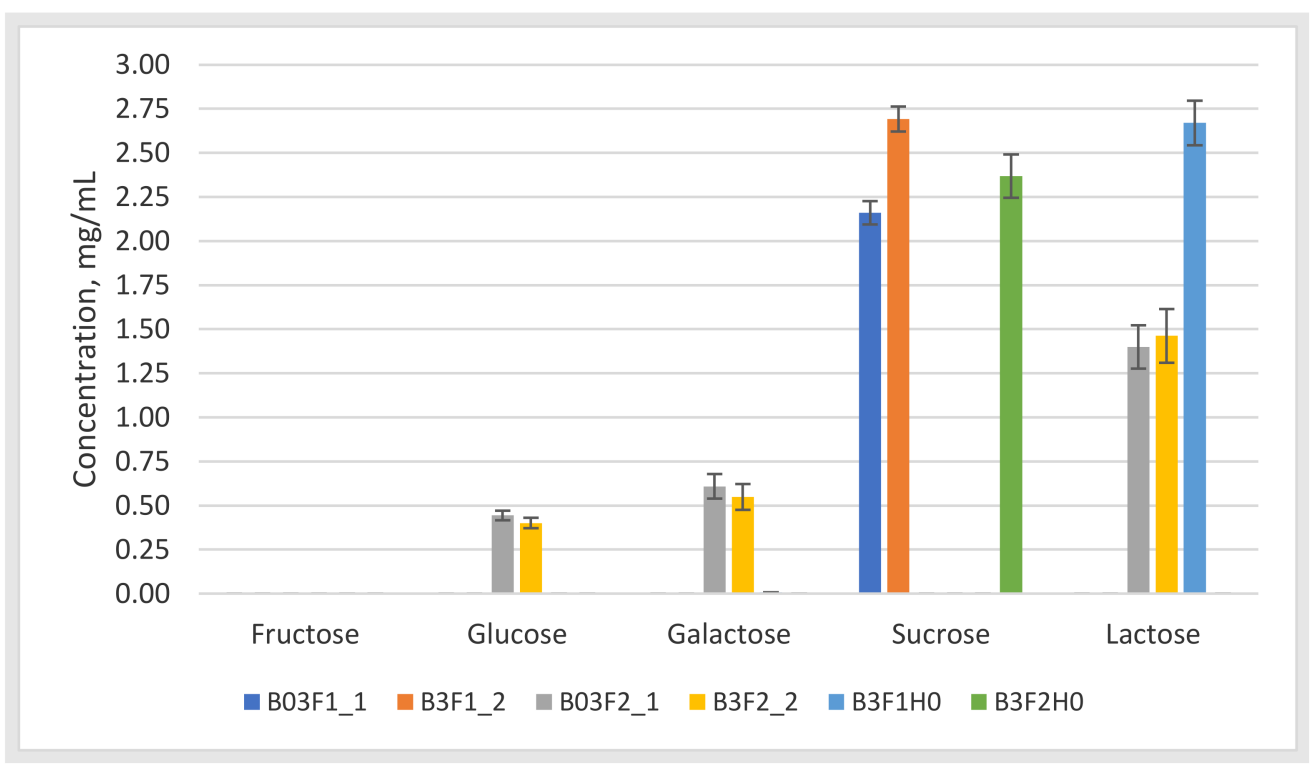

Figure 4. Quantified carbohydrates $(\mathrm{mg} / \mathrm{mL})$ in the measured samples. The bars represent the concentration levels of the found saccharides in the fermentation samples. The sample naming follows B stands for batch fermentation; number 3 or 03 states the number of experiments, F1 or F2 states the reactor number and_1 or_2 states the number of parallel. H0 denotes $0 \mathrm{~h}$ sampling point.

It was found that neither of the samples contained fructose at levels exceeding the limit of quantification. Other samples contained either sucrose or lactose at a higher concentration due to its presence in CDM. It was shown in samples B03F2_1 and B3F2_2 that the bacterium was able to produce monosaccharides by breaking down larger saccharide. In other samples, no by-products of disaccharide breakdown were detected, which could indicate that bacteria would utilise either sucrose or lactose as a carbon source for the production of other molecules such as organic acids. The results were subjected to carbon balance calculations based solely on the saccharide content in the fermented and blank samples. The calculations showed that measured saccharide content is correlatable with calculations e.g., carbon balance calculation errors were $25.6 \pm 16.1 \%(n=6)$ on average between fermented samples. The obtained values were found to be acceptable as calculations did not take into the account presence of other organic materials commonly present in the fermentation broth.

\subsection{Validation Results}

When the development and optimisation of methodology were finished, validation was performed to evaluate the method linear range, limits of detection and quantifications, recoveries and the stability of prepared samples. First of all, linear range and linearity were evaluated via the repeated measurements of standard solutions consisting of 8 individual points obtained from stock's serial dilution (Table 3). 
Table 3. The linear range, regression equation, limits of detection. and quantification of five saccharides.

\begin{tabular}{lccccc}
\hline Analyte & $\begin{array}{c}\text { Linear Range, } \\
\boldsymbol{\mu g} / \mathbf{m} \mathbf{l}\end{array}$ & Linear Regression & $\mathbf{R}^{\mathbf{2}}$ & $\mathbf{L o D}^{\mathbf{1}} \mathbf{, ~ \mathbf { ~ g } / \mathbf { L }}$ & $\mathbf{L o Q}^{\mathbf{2}} \mathbf{, ~ \mathbf { ~ g } / \mathbf { L }}$ \\
\hline Fructose & $0.77-49.88$ & $\mathrm{y}=1.3611 \mathrm{x}+0.9873$ & 0.9974 & 0.189 & 0.629 \\
Glucose & $0.51-64.80$ & $\mathrm{y}=0.6921 \mathrm{x}+0.0765$ & 0.9993 & 0.080 & 0.268 \\
Galactose & $0.39-49.60$ & $\mathrm{y}=0.3764 \mathrm{x}-0.0112$ & 0.9958 & 0.067 & 0.220 \\
Sucrose & $0.93-59.75$ & $\mathrm{y}=1.2610 \mathrm{x}+0.9776$ & 0.9935 & 0.232 & 0.704 \\
Lactose & $0.38-49.10$ & $\mathrm{y}=1.0851 \mathrm{x}-0.0076$ & 0.9996 & 0.048 & 0.159 \\
\hline
\end{tabular}

${ }^{1}$ LoD = Blank mean value $+3.3^{*}$ standard deviation at LLOQ; ${ }^{2}$ LoQ $=$ Blank mean value $+10^{*}$ standard deviation at LLOQ.

After linearity was found to be acceptable ( $2 \geq 0.99$ or higher) for all sugars in this study, the repeatability of the method was studied. Repeatability of retention times and peak areas were studied first with six replicate injections of standard solution (Table 4). The repeatability of the method was studied across four independent days to confirm the stability of the retentions time and peak areas of the analytes.

Table 4. Repeatability of retention times and peak areas of measured carbohydrates.

\begin{tabular}{|c|c|c|c|c|c|c|}
\hline \multirow{2}{*}{ Analyte } & \multirow{2}{*}{$\begin{array}{l}\text { Mass of } \\
\text { Measured } \\
\text { Ion, } \mathrm{m} / \mathrm{z}\end{array}$} & \multirow{2}{*}{$\begin{array}{l}\text { Retention } \\
\text { Time, min }\end{array}$} & \multicolumn{2}{|c|}{ Retention Time RSD, \% } & \multicolumn{2}{|c|}{ Peak Area RSD \% } \\
\hline & & & $\begin{array}{l}\text { Inter-Day, } \\
\%(n=6)\end{array}$ & $\begin{array}{l}\text { Intra-Day, } \\
\%(\mathrm{n}=4)\end{array}$ & $\begin{array}{l}\text { Inter-Day, } \\
\%(\mathrm{n}=6),\end{array}$ & $\begin{array}{l}\text { Intra-Day, } \\
\%(\mathrm{n}=4)\end{array}$ \\
\hline Fructose & 215 & 5.06 & 0.26 & 1.27 & 2.90 & 3.75 \\
\hline Glucose & 215 & 5.75 & 0.42 & 1.59 & 2.69 & 4.01 \\
\hline Galactose & 215 & 6.18 & 0.50 & 1.50 & 3.62 & 3.28 \\
\hline Sucrose & 377 & 8.16 & 0.23 & 1.32 & 3.46 & 2.96 \\
\hline Lactose & 377 & 9.81 & 0.19 & 1.60 & 4.70 & 2.40 \\
\hline Glucose $-{ }^{13} \mathrm{C}_{6}$ & 221 & 5.70 & 0.39 & 0.59 & 2.13 & 1.48 \\
\hline Lactose $-{ }^{13} \mathrm{C}_{6}$ & 383 & 9.73 & 0.44 & 0.50 & 4.63 & 2.23 \\
\hline
\end{tabular}

Recovery of the sample preparation was determined by analysing fermentation samples, whereas ${ }^{13} \mathrm{C}$-internal standards were spiked prior to sample preparation steps and compared to sample preparation procedure where ${ }^{13} \mathrm{C}$-internal standards were added in the last stage of the procedure. Recovery was calculated according to Equation (1):

Recovery $=$ Peak area in a spiked sample $/$ Peak area in a non-spiked sample $* 100$

The recovery experiments consisted of injections of 2 samples in triplicate. The recorded recovery values were $103.73 \pm 1.69 \%$ and $111.04 \pm 2.80 \%$ for ${ }^{13} \mathrm{C}$-labeled glucose and ${ }^{13} \mathrm{C}$-labeled lactose, respectively. The obtained values are in the $\pm 20 \%$ range. Furthermore, we have investigated the stability of the prepared standard solutions in a ready-to-use form stored at +4 and $-20{ }^{\circ} \mathrm{C}$. The prepared standards were stable at +4 degrees for one week whereas peak area of analytes has not changed by more than $5 \%$. The analytes stored at -20 degrees for 1 month showed stable retention factors or all measured compound except for sucrose, which response factor after 1 month of storage at $-20{ }^{\circ} \mathrm{C}$ had changed by $15 \%$.

\section{Materials and Methods}

\subsection{Reagents and Chemicals}

Standards of mono- and disaccharides: D-fructose, D-glucose, D-galactose, D-(+)sucrose, D-lactose monohydrate, and ammonia solution (25\%, LC-MS LiChropur ${ }^{\mathrm{TM}}$ grade) were obtained from Sigma-Aldrich (Darmstadt, Germany). Glucose- ${ }^{13} \mathrm{C}_{6}\left(\mathrm{Glu}^{-13} \mathrm{C}_{6}, \mathrm{U}_{-}{ }^{13} \mathrm{C}_{6}\right.$, $99 \%$, chemical purity $98 \%$ ) and lactose monohydrate (Lac- ${ }^{13} \mathrm{C}_{6}, \mathrm{UL}^{-1}{ }^{13} \mathrm{C}_{6} \mathrm{glc}, 98 \%+$ ) were procured from Cambridge Isotope Laboratories Inc. (Tewksbury, MA, USA). Ultrapure 
water (18.2 M $\Omega . c m$ ) was prepared with MilliQ ${ }^{\circledR}$ Direct- $\mathrm{Q}^{\circledR}$ UV (Merck KGaA, Darmstadt, Germany). Acetonitrile (MeCN; LiChrosolv, HPLC gradient grade), and guanidine hydrochloride ( $\mathrm{GuHCl} ; \geq 99 \%)$ were acquired from Sigma-Aldrich (Darmstadt, Germany). Biotage Isolute ${ }^{\circledR} \mathrm{PLD}+, \mathrm{C} 18$ and $\mathrm{NH}_{2}$ were procured from Biotage Sweden $\mathrm{AB}$ (Uppsala, Sweden). Amicon Ultra- 0.5 centrifugal filter unit $(3 \mathrm{kDa}$ ) and Millex-LCR filters (Pore size $0.2 \mu \mathrm{m}$, Filter Dimension $13 \mathrm{~mm}$ ) were obtained from Merck KGaA (Darmstadt, Germany) and Microsep Advance Centrifugal Devices with Omega Membrane 1K filter unit was purchased from Pall Corporation (Port Washington, NY, USA).

\subsection{Preparation of Standard Solutions}

The stock solution of each individual saccharide was prepared in MilliQ ${ }^{\circledR}$ water and stored at $-20^{\circ} \mathrm{C}$. Solutions of isotopically labelled standards were dissolved in aqueous $\operatorname{MeCN}(50 \%, v / v)$ and stored at $-50{ }^{\circ} \mathrm{C}$. Working solutions for the determination of analytes were prepared firstly by diluting the stock solution with $100 \% \mathrm{MeCN}$, and after each working solution was prepared in aqueous $\mathrm{MeCN}(50 \%, v / v)$ water. Calibration curves were built for fructose $(0.39-49.875 \mathrm{ppm})$, glucose $(0.506-64.800 \mathrm{ppm})$, galactose $(0.388$ $49.600 \mathrm{ppm})$, sucrose $(0.467-59.750 \mathrm{ppm})$ and lactose $(0.384-49.100 \mathrm{ppm})$. Glucose- ${ }^{13} \mathrm{C}_{6}$ and lactose- ${ }^{13} \mathrm{C}_{6}$ were added prior to injection to the autosampler vial, and their concentration in the vial was set at 15.925 and $12.825 \mathrm{ppm}$, respectively. The calculations of calibration curves used response factors, which were calculated according to Equation (2).

Response Factor $(\mathrm{RF})=$ Area of analytes $\times($ Concentration of internal standard $/$ Area of internal standard $)$

Calibration curves were built using eight-point measurements of serially diluted standards. The regression was found by fitting a point to a linear equation.

\subsection{Liquid Chromatography}

Samples were analysed using a Waters UPLC ${ }^{\circledR}$ system (Waters Corporation, Milford, MA, USA) coupled with a Waters Quattro Premier XE Mass Spectrometer equipped with ZSpray ${ }^{\mathrm{TM}}$ Source and controlled by Waters MassLynx ${ }^{\mathrm{TM}} 4.1$ (V4.1 SCN805, Waters Corporation, Milford, MA). Mobile phases were as follows: (A) $99 \% \mathrm{MilliQ}^{\circledR}+1 \% \mathrm{MeCN}+1 \mathrm{mg} / \mathrm{L}$ of $\mathrm{GuHCl}$ and (B) $99 \% \mathrm{MeCN}+1 \% \mathrm{MilliQ}^{\circledR}+1 \mathrm{mg} / \mathrm{L}$ of GuHCl . Weak needle wash was composed of $10 \%$ MilliQ $^{\circledR}$ in MeCN (v/v), and strong wash needle consisted of $10 \%$ MeCN in $\mathrm{MilliQ}^{\circledR}(v / v)$. Seal wash was aqueous $\mathrm{MeCN}(50 \%, v / v)$. Samples were stored at an autosampler which held temperature at $8{ }^{\circ} \mathrm{C}$. The injection volume was $2 \mu \mathrm{L}$. Several columns were tested: Waters Acquity UPLC ${ }^{\circledR}$ BEH HILIC $(2.1 \times 100 \mathrm{~mm}, 1.7 \mu \mathrm{m}$, Waters Corporation, Milford, MA), Waters XBridge ${ }^{\circledR}$ BEH Amide XP $(3.0 \times 150 \mathrm{~mm}, 2.5 \mu \mathrm{m}$, Waters Corporation, Milford, MA), Phenomenex Luna Omega Sugar column $(2.1 \times 150 \mathrm{~mm}$, $100 \AA$, $3 \mu \mathrm{m}$, Phenomenex Inc., Torrance, CA, USA). To prevent harm to any analytical column, ACQUITY UPLC Column in-line filter unit (Waters Corporation, Milford, MA) with installed $0.2 \mu \mathrm{m}$ stainless steel filter was used in all experiments with all tested columns. The column temperature was held at 25 degrees of Celsius for the duration of all experiments. The gradient was as follows: 0-10 min linear gradient $10-25 \% \mathrm{~A}, 10-12 \mathrm{~min}$ hold at $25 \% \mathrm{~A}, 12.01-14 \mathrm{~min}$ hold at $35 \% \mathrm{~A}, 14.01-18 \mathrm{~min}$ hold at $10 \% \mathrm{~A}$. Flow rate was set at $313 \mu \mathrm{L} / \mathrm{min}$.

\subsection{Mass Spectrometry}

The analytes were ionised under negative electrospray ionisation conditions with optimised source conditions. The source temperature was set at $120{ }^{\circ} \mathrm{C}$, high-purity nitrogen was fed into the source at $50 \mathrm{~L} / \mathrm{h}$ (cone) and $800 \mathrm{~L} / \mathrm{h}$ (desolvation) and heated to $350{ }^{\circ} \mathrm{C}$. The capillary voltage was set at $-2.3 \mathrm{kV}$, cone voltage at $25 \mathrm{~V}$ and extractor voltage $3 \mathrm{~V}$. The values for efficient ionisation were found by infusing a standard solution of individual saccharide (ca $25 \mathrm{ppm}$ ) in 50\% aqueous $\mathrm{MeCN}(v / v)$ at the combined flow from UPLC and integrated syringe pump at $250 \mu \mathrm{L} / \mathrm{min}$. For measurement of analytes, single ion monitoring (SIR) experiments were chosen as saccharides possess no valuable fragments for ubiquitous identification, therefore, making it unnecessary to perform multiple reaction 
monitoring (MRM) type of experiments. The SIR channels were based on molecular ion with added chloride as $[\mathrm{M}+\mathrm{Cl}]^{-}$. Data acquisition was performed in Waters MassLynx ${ }^{\mathrm{TM}}$ V4.1 (SCN805, Waters Corporation, Milford, MA, USA). Data analysis was performed in Waters QuanLynx ${ }^{\mathrm{TM}}$ V4.1 (SCN805, Waters Corporation, Milford, MA, USA) and Microsoft Excel (Microsoft 365 Apps for enterprise).

\subsection{Bioreactor Experiments, Bacteria Growth Description}

Streptococcus thermophilus was inoculated into fresh M17 medium (lactose as carbon source) at the rate of $1 \mathrm{e}^{7} \mathrm{cfu} / \mathrm{mL}(1 \%)$ and cultivated until $\mathrm{OD}_{600}$ reached a value of 0.8 . Then the culture was inoculated into a bioreactor containing $300 \mathrm{~mL}$ of $\mathrm{CDM}$ achieving 100 -fold dilution. CDM contained either sucrose or lactose as a carbon source. Cultivation was conducted in anaerobic conditions maintained by the constant flow of $\mathrm{N}_{2}$ into the medium flask and $\mathrm{N}_{2}: \mathrm{CO}_{2}$ mixture $(80: 20, v / v)$ into the reactor vessel at 150 and $300 \mathrm{~mL} / \mathrm{min}$, respectively.

Culture outgrowth was monitored by the rate of medium acidification and using the turbidimetric sensor. After $7 \mathrm{~h}$ of batch growth, the stability of culture was achieved, and flowthrough was initiated with a dilution rate of $0.25 \mathrm{~h}^{-1}$. The flow was maintained for $20 \mathrm{~h}$, ensuring culture stabilisation. At the chemostat point, the culture samples were taken for subsequent analysis. HPLC samples were centrifuged at 14,000 rpm for $10 \mathrm{~min}$. Supernatants were frozen and stored at $-20^{\circ} \mathrm{C}$.

\subsection{Sample Preparation}

Frozen samples were fully thawed at room temperature until a clear solution was obtained. Thawed samples were serially diluted 100-fold before further steps. Diluted samples $(1000 \mu \mathrm{L})$ were firstly centrifuged at $14,000 \mathrm{rpm}$ for $10 \mathrm{~min}$ to remove any remaining solid residue. The supernatant $(500 \mu \mathrm{L})$ was then transferred to a $3 \mathrm{kDa}$ molecular weight cut-off (MWCO) filter (Amicon ${ }^{\circledR}$ Ultra-0.5, Merck KGaA, Germany). The MWCO filter was then centrifuged at 14,000 $\mathrm{rpm}$ for $20 \mathrm{~min}$. The supernatant obtained was diluted with a $50 \%$ aqueous $\mathrm{MeCN}(v / v)$ mixture containing Glu- ${ }^{13} \mathrm{C}_{6}$ and Lac- ${ }^{13} \mathrm{C}_{6} 2$-fold before analysis.

\subsection{Method Validation}

The developed method was assessed for linearity (as a correlation coefficient of $\mathrm{R}^{2}$ of calibration curve), the limit of detection and quantification (as the standard deviation of the measured sample at the lowest calibration points multiplied by 3 or 10, respectively), recovery (as spiked sample vs. un-spiked) and matrix effect [31].

\section{Conclusions}

In summary, we have developed the HILIC-LC-MS method for the rapid and simultaneous determination of five saccharides in just $18 \mathrm{~min}$ without employing complex sample preparations steps. The methodology can be applied to the simplest instrumentation consisting of liquid chromatograph and single quadrupole mass detector. The addition of a common mobile phase additive such as guanidine hydrochloride is a viable option to increase signal insensitivities while reducing the baseline noise. The mass spectrometric detection helps with the selectivity of the methodology as mass spectrometer could filter out matrix interfering components thus providing cleaner and unambiguous spectra. The simultaneous measurement of fructose, glucose, galactose, sucrose, and lactose could be done in a fraction of time and less consumed solvent compared to classical methods used elsewhere $[10,11,16,32]$. The method developed here suits for both to identify and characterise the metabolism of various starter cultures (like here with Streptococcus thermophilus) as well as to detect the sugar profile of different food matrices. Furthermore, the monosaccharide quantities could be used in a calculation of the carbon balance in a single cell model (SCM) to assess the productivity of the strain during fermentation. The applicability of the method for quantification of the larger oligosaccharide chains together with smaller 
saccharides, for example, to analyse their consumption by gut microbiota, could be further determined in the future.

Supplementary Materials: Figure S1: The chromatogram of 5 saccharides subjected to the optimised gradient elution program with flow rate of $300 \mu \mathrm{L} / \mathrm{min}$, Figure S2: The chromatogram of 5 saccharides subjected to the optimised gradient elution program with flow rate of $313 \mu \mathrm{L} / \mathrm{min}$, Figure S3: The chromatogram of 5 saccharides subjected to the optimised gradient elution program with flow rate of $350 \mu \mathrm{L} / \mathrm{min}$, Table S1: The peak areas of analytes while using neat solvents or solvents with added guanidine hydrochloride, Table S2: The peak areas of five saccharides in this study subjected to different extraction protocol in order to perform the sample preparation optimisation.

Author Contributions: Conceptualisation, D.P., V.K. and R.V.; methodology, D.P.; software, V.K.; validation, D.P. and V.K.; formal analysis, D.P. and V.K.; investigation, D.P., V.K. and J.M.; resources, V.K. and J.M.; data curation, D.P. and V.K.; writing-original draft preparation, D.P.; writing—review and editing, J.M., M.-L.K., R.V.; visualisation, D.P.; supervision, R.V.; project administration, D.P.; funding acquisition, M.-L.K. and R.V. All authors have read and agreed to the published version of the manuscript.

Funding: This study was supported by ERDF and Estonian Research Council via project RESTA16.

Institutional Review Board Statement: Not applicable.

Informed Consent Statement: Not applicable.

Data Availability Statement: Data is contained within the article.

Acknowledgments: Authors would like to acknowledge Tiina Kriščiunaite and Georg Arju for input in the editing of the manuscript.

Conflicts of Interest: The authors declare no conflict of interest.

Sample Availability: Not available.

\section{References}

1. Hutkins, R.; Goh, Y.J. STREPTOCOCCUS I Streptococcus thermophilus. In Encyclopedia of Food Microbiology; Elsevier: Amsterdam, The Netherlands, 2014; pp. 554-559. ISBN 978-0-12-384733-1.

2. Thomas, T.D.; Crow, V.L. Lactose and Sucrose Utilization by Streptococcus Thermophilus. FEMS Microbiol. Lett. 1983, 17, 13-17. [CrossRef]

3. Sobowale, A.A.; Efuntoye, M.O.; Adesetan, O.O. Energy Sources of Yoghurt Bacteria and Enhancement of Their Galactose Uptake. Afr. J. Biotechnol. 2011, 10, 4457-4463. [CrossRef]

4. Robitaille, G.; Moineau, S.; St-Gelais, D.; Vadeboncoeur, C.; Britten, M. Galactose Metabolism and Capsule Formation in a Recombinant Strain of Streptococcus Thermophilus with a Galactose-Fermenting Phenotype. J. Dairy Sci. 2007, 90, $4051-4057$. [CrossRef] [PubMed]

5. Jermyn, M.A.; Isherwood, F.A. Improved Separation of Sugars on the Paper Partition Chromatogram. Biochem. J. 1949, 44, 402-407. [CrossRef] [PubMed]

6. Noggle, G.R.; Zill, L.P. The Biosynthesis of Carbon-14-Labeled Compounds. III. The Separation and Isolation of Sugars by Ion-Exchange Chromatography1. Plant Physiol. 1953, 28, 731-735. [CrossRef]

7. Bishop, C.T.; Cooper, F. Separation Of Carbohydrate Derivatives By Gas-Liquid Partition Chromatography. Can. J. Chem. 1960. [CrossRef]

8. Wheaton, R.M.; Bauman, W.C. Ion Exclusion-A Unit Operation Utilizing Ion Exchange Materials. Ind. Eng. Chem. 1953, 45, 228-233. [CrossRef]

9. Weiß, K.; Alt, M. Determination of Single Sugars, Including Inulin, in Plants and Feed Materials by High-Performance Liquid Chromatography and Refraction Index Detection. Fermentation 2017, 3, 36. [CrossRef]

10. Correia, D.M.; Dias, L.G.; Veloso, A.C.A.; Dias, T.; Rocha, I.; Rodrigues, L.R.; Peres, A.M. Dietary Sugars Analysis: Quantification of Fructooligossacharides during Fermentation by HPLC-RI Method. Front. Nutr. 2014, 1. [CrossRef]

11. Zielinski, A.A.F.; Braga, C.M.; Demiate, I.M.; Beltrame, F.L.; Nogueira, A.; Wosiacki, G. Development and Optimization of a HPLC-RI Method for the Determination of Major Sugars in Apple Juice and Evaluation of the Effect of the Ripening Stage. Food Sci. Technol. 2014, 34, 38-43. [CrossRef]

12. Montesano, D.; Cossignani, L.; Giua, L.; Urbani, E.; Simonetti, M.S.; Blasi, F. A Simple HPLC-ELSD Method for Sugar Analysis in Goji Berry. Available online: https://www.hindawi.com/journals/jchem/2016/6271808/ (accessed on 2 February 2021).

13. Oliver, J.D.; Sutton, A.T.; Karu, N.; Phillips, M.; Markham, J.; Peiris, P.; Hilder, E.F.; Castignolles, P. Simple and Robust Monitoring of Ethanol Fermentations by Capillary Electrophoresis. Biotechnol. Appl. Biochem. 2015, 62, 329-342. [CrossRef] 
14. Herber, W.K.; Robinett, R.S.R. Determination of Carbon Sources in Fermentation Media Using High-Performance Anion-Exchange Liquid Chromatography and Pulsed Amperometric Detection. J. Chromatogr. A 1994, 676, 287-295. [CrossRef]

15. Robinett, R.S.R.; Herber, W.K. Analysis of Substrates and Metabolites in Fermentation Broth by Ion Chromatography. J. Chromatogr. A 1994, 671, 315-322. [CrossRef]

16. Oliver, J.D.; Gaborieau, M.; Hilder, E.F.; Castignolles, P. Simple and Robust Determination of Monosaccharides in Plant Fibers in Complex Mixtures by Capillary Electrophoresis and High Performance Liquid Chromatography. J. Chromatogr. A 2013, 1291, 179-186. [CrossRef]

17. Krol, J. Simple Sugar Analysis by HPLC Using Refractive Index Detection. Available online: http:/ / www.waters.com/waters / library.htm?lid=1543489 (accessed on 2 February 2021).

18. Schuster-Wolff-Bühring, R.; Michel, R.; Hinrichs, J. A New Liquid Chromatography Method for the Simultaneous and Sensitive Quantification of Lactose and Lactulose in Milk. Dairy Sci. Technol. 2011, 91, 27-37. [CrossRef]

19. Clement, A.; Yong, D.; Brechet, C. Simultaneous Identification of Sugars by HPLC Using Evaporative Light Scattering Detection (ELSD) and Refractive Index Detection (RI). Application to Plant Tissues. J. Liq. Chromatogr. 1992, 15, 805-817. [CrossRef]

20. Zhang, Q.; Bailey, B.; Thomas, D.; Plante, M.; Acworth, I. Direct Carbohydrate Analysis in Beverages and Foods Using Pulsed Amperometric Detection or Charged Aerosol Detection; Thermo Fisher Scientific: Chelmsford, MA, USA, $2015 ;$ p. 7.

21. Gervasoni, J.; Primiano, A.; Graziani, C.; Scaldaferri, F.; Gasbarrini, A.; Urbani, A.; Persichilli, S. Validation of UPLC-MS/MS Method for Determination of Urinary Lactulose/Mannitol. Molecules 2018, 23, 2705. [CrossRef]

22. Rego, A.; Jesus, S.; Motta, C.; Delgado, I.; Teixeira, R.; Galhano dos Santos, R.; Castanheira, I. Quantification by LC-MS/MS of Individual Sugars in Fruit Juice Consumed in Portugal. J. Phys. Conf. Ser. 2018, 1065, 232004. [CrossRef]

23. Bawazeer, S.; Muhsen Ali, A.; Alhawiti, A.; Khalaf, A.; Gibson, C.; Tusiimire, J.; Watson, D.G. A Method for the Analysis of Sugars in Biological Systems Using Reductive Amination in Combination with Hydrophilic Interaction Chromatography and High Resolution Mass Spectrometry. Talanta 2017, 166, 75-80. [CrossRef]

24. Gleave, M. The Strengths of Mass Spectrometry Are Not Just Sensitivity and Selectivity. Bioanalysis 2011, 3, 245-247. [CrossRef]

25. Fountain, K.J.; Hudalla, C.; Grumbach, E.S.; McCabe, D.; Morrison, D. Analysis of Carbohydrates by UltraPerformance Liquid Chromatography and Mass Spectrometry. Available online: https://www.waters.com/nextgen/ee/en/library/applicationnotes / 2009/analysis-of-carbohydrates-by-uplc-and-mass-spectrometry.html (accessed on 3 February 2021).

26. Thacker, J.B.; Schug, K.A. Quantitative Determination of Fructose, Glucose, and Sucrose in Hard Ciders and Apple Juice by LC-MS/MS. Sep. Sci. PLUS 2020, 3, 286-293. [CrossRef]

27. Boutegrabet, L.; Kanawati, B.; Gebefügi, I.; Peyron, D.; Cayot, P.; Gougeon, R.D.; Schmitt-Kopplin, P. Attachment of Chloride Anion to Sugars: Mechanistic Investigation and Discovery of a New Dopant for Efficient Sugar Ionization/Detection in Mass Spectrometers. Chem. Weinh. Bergstr. Ger. 2012, 18, 13059-13067. [CrossRef] [PubMed]

28. Jiang, Y.; Cole, R.B. Oligosaccharide Analysis Using Anion Attachment in Negative Mode Electrospray Mass Spectrometry. J. Am. Soc. Mass Spectrom. 2005, 16, 60-70. [CrossRef] [PubMed]

29. Jenkins, K. HILIC Separation of Carbohydrates Using BEH Amide Particle Technology. Available online: https://www. chromatographytoday.com/article/bioanalytical/40/waters-corporation/hilic-separation-of-carbohydrates-using-behamide-particle-technology/1959 (accessed on 3 March 2021).

30. Letort, C.; Juillard, V. Development of a Minimal Chemically-Defined Medium for the Exponential Growth of Streptococcus Thermophilus. J. Appl. Microbiol. 2001, 91, 1023-1029. [CrossRef] [PubMed]

31. Kruve, A.; Rebane, R.; Kipper, K.; Oldekop, M.-L.; Evard, H.; Herodes, K.; Ravio, P.; Leito, I. Tutorial Review on Validation of Liquid Chromatography-Mass Spectrometry Methods: Part II. Anal. Chim. Acta 2015, 870, 8-28. [CrossRef] [PubMed]

32. Xu, W.; Liang, L.; Zhu, M. Determination of Sugars in Molasses by HPLC Following Solid-Phase Extraction. Int. J. Food Prop. 2015, 18, 547-557. [CrossRef] 